\title{
Crystal Structure of $\alpha$-( $p$-Methylylamino-o-nitrobenzyl)pyridine
}

\author{
Isao FuJII*, Kazumi TANAKA**, Takashi DeguchI** and Noriaki HirayaMA* \\ * Department of Biological Science and Technology, Tokai University, \\ Nishino, Numazu, Shizuoka 410-0321, Japan \\ **Kyowa Toxicological Research Laboratories, Kyowa Hakko Kogyo Co. Ltd., \\ 2540 Ooaza Fujimagari, Ube, Yamaguchi 755, Japan
}

It was found that $\alpha$-( $p$-butylylamino-o-nitrobenzyl) pyridine (I) (Fig. 1) has an ameliorative effect on learning and memory in various experimental amnesia models of rodents, and increases the contents of monoamines. ${ }^{1}$ The title compound (II) (Fig. 1) is one of the derivatives; an X-ray analysis was undertaken in order to determine the inherent conformation and to study the structure-activity relationships.

A pale-yellow prism crystal $(0.3 \times 0.2 \times 0.1 \mathrm{~mm})$ was<smiles>CCCC(=O)Nc1ccc(Cc2ccccn2)c([N+](=O)[O-])c1</smiles><smiles>CC(=O)Nc1ccc(Cc2ccccn2)c([N+](=O)[O-])c1</smiles>

(II)

Fig. 1 Chemical structures.

Table 1 Crystal and experimental data

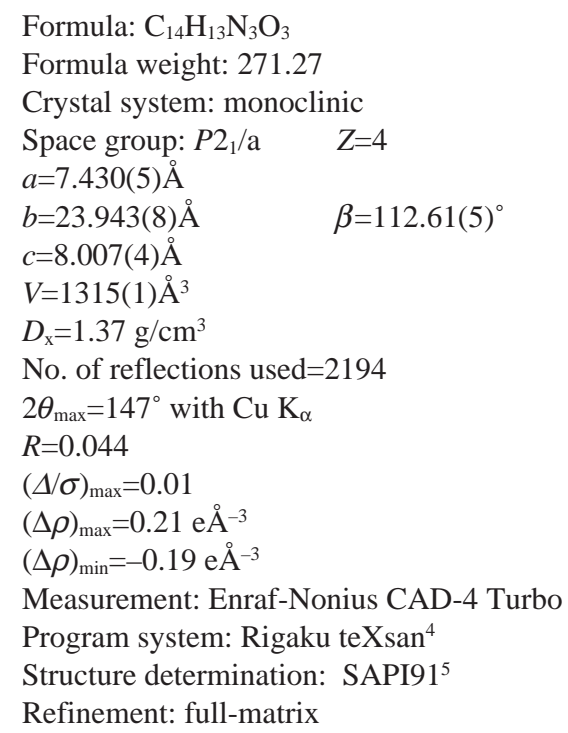

Formula: $\mathrm{C}_{14} \mathrm{H}_{13} \mathrm{~N}_{3} \mathrm{O}_{3}$

Formula weight: 271.27

al system: monoclinic

$a=7.430(5) \AA$

$b=23.943(8) \AA \quad \beta=112.61(5)^{\circ}$

$D_{\mathrm{x}}=1.37 \mathrm{~g} / \mathrm{cm}^{3}$

No. of reflections used=2194

$2 \theta_{\max }=147^{\circ}$ with $\mathrm{Cu} \mathrm{K}$

$(\Delta \rho)_{m}=-0.19 \mathrm{e}^{-3}$

Measurement: Enraf-Nonius CAD-4 Turbo

Structure determination: SAPI91

Refinement: full-matrix

obtained from an acetone solution at 293(5)K. The crystal and experimental data are given in Table 1. The structure was solved by direct methods and refined by full-matrix least-squares methods with anisotropic temperature factors for non- $\mathrm{H}$ atoms. All $\mathrm{H}$ atoms were found from difference Fourier maps and refined isotropically. The atomic parameters for non-hydrogen atoms are listed in Table 2.

Selected bond distances and angles are listed in Table 3. An ORTEP $\mathrm{II}^{2}$ drawing of the title compound together with the atomic numbering is shown in Fig. 2. The relative orientation of the pyridine and phenyl

Table 2 Atomic coordinates and equivalent isotropic thermal parameters $\left(B_{\text {eq }}\right)$

\begin{tabular}{|c|c|c|c|c|}
\hline Atom & $x$ & $y$ & $z$ & $B_{\text {eq }}$ \\
\hline 01 & $0.6801(3)$ & $0.29190(7)$ & $0.8620(3)$ & $6.53(5)$ \\
\hline 02 & $0.5026(3)$ & $0.34459(7)$ & $0.9519(3)$ & $6.10(5)$ \\
\hline 03 & $0.3037(3)$ & $0.50637(8)$ & $0.6934(3)$ & $6.69(5)$ \\
\hline $\mathrm{N} 1$ & $1.1556(3)$ & $0.36756(7)$ & $1.2997(2)$ & $4.12(4)$ \\
\hline N2 & $0.6356(3)$ & $0.33777(7)$ & $0.9006(2)$ & $4.09(4)$ \\
\hline$\times 3$ & $0.6085(3)$ & $0.53236(7)$ & $0.7227(3)$ & $3.92(4)$ \\
\hline $\mathrm{Cl}$ & $1.0419(4)$ & $0.27418(9)$ & $1.2396(3)$ & $4.54(5)$ \\
\hline $\mathrm{C} 2$ & $1.0663(4)$ & $0.2672(1)$ & $1.4172(3)$ & $5.32(6)$ \\
\hline $\mathrm{C} 3$ & $1.1357(4)$ & $0.3107(1)$ & $1.5362(4)$ & $5.36(6)$ \\
\hline $\mathrm{C} 4$ & $1.1765(4)$ & $0.3600(1)$ & $1.4698(3)$ & $5.07(6)$ \\
\hline $\mathrm{C} 5$ & $1.0877(3)$ & $0.32465(7)$ & $1.1830(3)$ & $3.32(4)$ \\
\hline c6 & $1.0686(4)$ & $0.33477(9)$ & $0.9915(3)$ & $3.90(5)$ \\
\hline$c 7$ & $0.9370(3)$ & $0.38370(8)$ & $0.9029(2)$ & $3.19(4)$ \\
\hline $\mathrm{c8}$ & $0.7403(3)$ & $0.38698(7)$ & $0.8758(2)$ & $3.19(4)$ \\
\hline $\mathrm{Cg}$ & $0.6283(3)$ & $0.43472(8)$ & $0.8207(3)$ & $3.41(4)$ \\
\hline $\mathrm{C} 10$ & $0.7109(3)$ & $0.48183(8)$ & $0.7777(3)$ & $3.36(4)$ \\
\hline $\mathrm{C} 11$ & $0.9030(3)$ & $0.47900(9)$ & $0.7918(3)$ & $3.62(4)$ \\
\hline $\mathrm{C} 12$ & $1.0122(3)$ & $0.43137(8)$ & $0.8567(3)$ & $3.48(4)$ \\
\hline $\mathrm{C} 13$ & $0.4167(3)$ & $0.5422(1)$ & $0.6864(3)$ & $4.26(5)$ \\
\hline $\mathrm{C} 14$ & $0.3524(5)$ & $0.6013(1)$ & $0.6349(4)$ & $5.04(6)$ \\
\hline
\end{tabular}

$B_{\mathrm{eq}}=\left(8 \pi^{2} / 3\right) \sum_{i} \Sigma_{j} U_{i j} a_{i}^{*} a_{j}^{*}\left(\boldsymbol{a}_{i} \cdot \boldsymbol{a}_{j}\right)$. 
Table 3 Selected bond distances $(\AA)$ and angles $\left({ }^{\circ}\right)$

\begin{tabular}{|c|c|c|c|c|c|c|c|}
\hline $01---$ N2 & \multicolumn{2}{|c|}{$1.220(2)$} & \multicolumn{2}{|c|}{$02---\mathrm{N} 2$} & $1.218(2)$ & $03---\mathrm{C} 13$ & $1.217(3)$ \\
\hline N1 --- C4 & \multicolumn{2}{|c|}{$1.322(3)$} & \multicolumn{2}{|c|}{ N1 --- C5 } & $1.349(2)$ & N2 $---\mathrm{C} 8$ & $1.466(2)$ \\
\hline N3 --- 10 & \multicolumn{2}{|c|}{$1.407(3)$} & $\mathrm{N} 3-$ & $-\mathrm{C} 13$ & $1.362(3)$ & & \\
\hline \multicolumn{2}{|c|}{$C 4---N 1---C 5$} & \multicolumn{2}{|c|}{$118.3(2)$} & \multicolumn{2}{|c|}{$01---12---02$} & \multicolumn{2}{|l|}{$122.7(2)$} \\
\hline \multicolumn{2}{|c|}{01 --- N2 --- C8 } & \multicolumn{2}{|c|}{$118.6(2)$} & \multicolumn{2}{|c|}{$02---$ N2 --- C8 } & \multicolumn{2}{|l|}{$118.6(2)$} \\
\hline \multicolumn{2}{|c|}{$\mathrm{C} 10---\mathrm{N} 3---\mathrm{C} 13$} & \multicolumn{2}{|c|}{$127.8(2)$} & \multicolumn{2}{|c|}{ N1 --- C4 --- C3 } & \multicolumn{2}{|l|}{$124.0(2)$} \\
\hline \multicolumn{2}{|c|}{$\mathrm{N} 1---\mathrm{C} 5--\mathrm{Cl}$} & \multicolumn{2}{|c|}{$120.9(2)$} & \multicolumn{2}{|c|}{$\mathrm{N} 1--\mathrm{C} 5--\mathrm{C} 6$} & \multicolumn{2}{|l|}{$116.6(2)$} \\
\hline \multicolumn{2}{|c|}{ N2 --- $\mathrm{C} 8--\mathrm{C} 7$} & \multicolumn{2}{|c|}{$120.8(2)$} & \multicolumn{2}{|c|}{ N2 --- C8 --- C9 } & \multicolumn{2}{|l|}{$115.0(2)$} \\
\hline \multicolumn{2}{|c|}{ N3 --- C10--- C9 } & \multicolumn{2}{|c|}{$122.6(2)$} & \multicolumn{2}{|c|}{ N3 $---\mathrm{C} 10---\mathrm{C} 11$} & \multicolumn{2}{|l|}{$118.9(2)$} \\
\hline \multicolumn{2}{|c|}{$03---C 13---N 3$} & \multicolumn{2}{|c|}{$123.4(2)$} & \multicolumn{2}{|c|}{$03---\mathrm{C} 13---\mathrm{C} 14$} & \multicolumn{2}{|l|}{$121.7(2)$} \\
\hline \multicolumn{2}{|c|}{ N3 --- C13--- C14 } & \multicolumn{4}{|c|}{$114.8(2)$} & & \\
\hline
\end{tabular}

rings is different from that of (I). ${ }^{3}$ The two rings are almost perpendicular to each other. The dihedral angle between the least-squares planes of the rings is $88.5(3)^{\circ}$, which is $88.8(5)^{\circ}$ in (I). The torsion angles of N1-C5-C6-C7 and C5-C6-C7-C12 in (II) are -57.9(3) and $-113.6(2)^{\circ}$, respectively. In (I) they are $-20.5(2)$ and $-81.9(2)^{\circ}$, respectively. The nitro group is markedly twisted out of the phenyl ring [O1-N2-C8-C7 33.8(3) $\left.{ }^{\circ}\right]$. The magnitude of the torsion angle is significantly larger than that of $20.3(2)^{\circ}$ in (I). In the present compound the amide group is slightly twisted out of the phenyl ring [C9-C10-N3-C13 6.7(3) ${ }^{\circ}$, O3-C13-N3-C10 1.9(4) $)^{\circ}$. The amide group, however, is considerably rotated from coplanarity with the phenyl ring in (I) [C9-C10-N3-C13 $\left.140.8(1)^{\circ}\right]$. The bond distances and angles in the molecule are within the normal ranges. There is an intermolecular hydrogen bond between the nitrogen atoms in the amide group and the pyridine ring [N1 $\cdots \mathrm{N} 3(2-x$, $\left.1-y, 2-z)=3.014(3) \AA, \angle \mathrm{N} 1 \cdots \mathrm{H}-\mathrm{N} 3=177(2)^{\circ}\right]$.

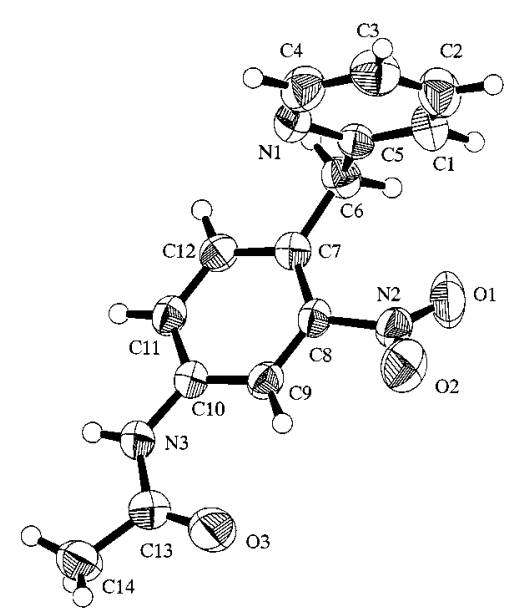

Fig. 2 ORTEPII drawing of the molecule, representing heavy atoms as $50 \%$ probability ellipsoids and $\mathrm{H}$ atoms as spheres of arbitrary radius.

\section{References}

1. A. Mori, M. Kurokawa, S. Shozaki, A. Ishii and K. Shuto, "Basic, Clinical and Therapeutic Aspects of Alzheimer's and Parkinson's Deseases", Vol. 2, pp. 445 -448, ed. T. Nagatsu, Plenum Press, New York, 1990.

2. C. K. Johnson, "ORTEP-II, A FORTRAN ThermalEllipsoid Plot Program”, Report ORNL-5138, Oak Ridge National Laboratory, Tennessee, U. S. A. (1976).

3. I. Fujii, K. Tanaka, T. Deguchi and N. Hirayama, Anal. Sci., 14, 1035 (1998).

4. teXsan, "Single Crystal Structure Analysis Software, Version 1.6", Molecular Structure Corporation, Texas, U. S. A. (1993).

5. H. -F. Fan, (1991). R-SAPI91: Structure Analysis Programs with Intelligent Control, Rigaku Corporation, Tokyo, Japan. 